\title{
Bicentenario de la Independencia de Colombia. CAUSAS DE LA INDEPENDENCIA HISPANOAMÉRICA Y DE COLOMBIA
}

Yecyd Alfonso Pardo Villalba. Egresado de la Facultad de derecho de la Universidad Santo Tomás en mayo 2009. Estudiante de Postgrado en derecho administrativo de la Universidad Santo Tomás 2009-2

E-mail: yepar139@yahoo.com , ypardov@superservicios.gov.co

Fecha de entrega: Noviembre 17 de 2009

Fecha de Aprobación: Noviembre 24 de 2009

Causas de la Independencia del 20 de Julio de 1810

RESUMEN: Según la historia oficial de lo que hoy conocemos como República de Colombia, el 20 de julio de 1810 fue una fecha gloriosa, motivo de orgullo y celebración porque marca una línea en el tiempo que transcribió el destino de esta patria, como lo es, la independencia de la corona española y la soberanía como un país independiente y libre; sin embargo queda en el ambiente académico algunos puntos por resolver, como lo son las causas reales que llevaron a la sublevación criolla contra los encomenderos de la corona española en el Virreinato de la Nueva Granada.

ABSTRACT: According to the official history of that we know today as the Republic of Colombia, on July 20 of 1810 was a glorious day, is a source of pride and 
celebration, because this marks a line in the time that transcribed while the fate of this country, as is the independence of the Spain crown and sovereignty as an country independent and free; nevertheless remains in the academic setting to resolve some points, as are the real causes that led to the uprising against the Creoles encomenderos the crown in the Spanish Viceroyalty of Nueva Granada.

PALABRAS CLAVES: Causas de la Independencia, independencia de Colombia, historia de Colombia, soberanía.

KEY WORDS: Cause of Independence, Independence of Colombia, Colombia History, Sovereignty.

\section{A PROPÓSITO DEL BICENTENARIO DE LA INDEPENDENCIA DE LA REPÚBLICA DE COLOMBIA}

En muchos países americanos que alguna vez fueron colonias de las naciones colonizadoras europeas se avecina un ambiente festivo y de celebración, en el marco de la conmemoración de doscientos años de haber logrado la independencia y constituirse como república libre e independiente, en el caso de los países colonizados por la corona española, las celebraciones bicentenarias iniciaron desde la ciudad de La Paz, que celebro la emancipación como república independiente, siendo la fecha oficial de independencia el 25 de mayo de 1809, a esta se le suma Ecuador quien en el 2009 también festeja su bicentenario independentista, y así se suman otras naciones en el 2010 (Venezuela, Argentina, Colombia, México y Chile). 


\section{REVISTA VIRTUAL VIA INVENIENDI ET IUDICANDI \\ "CAMINO DEL HALLAZGO Y DEL JUICIO"}

http://viei.usta.edu.co/ E-MAIL: revistainveniendi@usantotomas.edu.co

En Colombia, se estarían completando 200 años de independencia ya que según la fecha oficial nuestra independencia fue el 20 de Julio de 1810, y ya vemos como el gobierno nacional prepara un sinnúmero de actividades a propósito del bicentenario como bien lo relata el libro de Luis Javier Caicedo editado en Medellín en el 2005 y que hace un recorrido por las iniciativas que se han presentado para la conmemoración de la independencia Colombiana y de los demás pueblos de latinoamericana ${ }^{1}$. Dentro de las políticas públicas del gobierno nacional, destaco el Decreto 446 de febrero del 2008 por medio del cual se crea la alta Consejería Para el Bicentenario de la Independencia. ${ }^{2}$

Para la academia, es una gran oportunidad de exponer las dudas y reflexiones que giran en torno a la gesta independentista y la descripción oficial de los acontecimientos de la época de la revolución criolla que dieron como consecuencia el acta de Santa Fe del 20 de Julio de 1810; por lo que nuestro centro de interés en el semillero de Investigación en Historia del derecho "El Camino Andado" es hacer un acercamiento a las causas de la independencia de Colombia, con el firme propósito de enriquecer el debate académico sobre el tema y hacer un acercamiento histórico a este suceso de nuestra historia patria.

\section{REFLEXIONES SOBRE LAS CAUSAS DE LA INDEPENDENCIA DE COLOMBIA}

1

CAICEDO, Luis Javier, "1810 - 2010 Bicentenario de la Independencia de Colombia y Latinoamericana" editorial Artes y Letras LTDA. Medellin, Colombia 2005

2

Decreto 446 de 2008, por medio del cual se crea la Alta Consejería Para El Bicentenario de la Independencia, cuyo objetivo principal es "asesorar al Gobierno Nacional en temas relacionados con la celebración de acuerdos y convenios de cooperación educativos y culturales, nacionales e internacionales, encaminados a garantizar el desarrollo de programas y actividades con ocasión del Bicentenario de la Independencia". 


\section{REVISTA VIRTUAL VIA INVENIENDI ET IUDICAND\|}

"CAMINO DEL HALLAZGO Y DEL JUICIO"

http://viei.usta.edu.co/ E-MAIL: revistainveniendi@usantotomas.edu.co

a lo largo de un tiempo, en el semillero de investigación en Historia del Derecho "El camino Andado" de la Facultad de Derecho de la Universidad Santo Tomas, se ha venido haciendo un barrido histórico y una aproximación a lo que pueden ser las causas más que próximas y de mayor trascendencia que aportaron a la sublevación criolla en contra del país colonizador; para ello nuestra primera herramienta de estudio y plataforma para adentrarnos en las principales causas de la independencia va a ser el documento que fue elaborado a propósito de la conmemoración de un siglo y medio de las independencias de las naciones hispanas en la ciudad de Madrid, de acuerdo a la siguiente metodología:

- Causas generales de las independencias latinoamericanas

- Causas de la independencia del Nuevo Reino de la Nueva Granada

a) Causas externas

b) Causas internas

Con el orden metodológico propuesto, podemos hacer un recuento y unos comentarios acerca de las causas de la Independencia de Colombia, viniendo desde lo general y abstracto como lo son las causas generales de las independencias hispanoamericanos y llegar a como concretamente lo que pasaba en otros países y latitudes (causas externas) se condensaron en la realidad propia de la época (causas internas) y llegar a la gran conclusión la cual es el acta del 20 de julio de 1810.

\section{- Causas Generales de las Independencias Hispanoamericanas}

Durante la celebración del congreso de historia Latinoamericana, donde ponencias de reconocidos historiadores de la época proponen una serie de eventos para que al igual que nosotros tener una claridad mayor de la verdadera causalidad que 


\section{REVISTA VIRTUAL VIA INVENIENDI ET IUDICANDI \\ "CAMINO DEL HALLAZGO Y DEL JUICIO"}

http://viei.usta.edu.co/ E-MAIL: revistainveniendi@usantotomas.edu.co

tuvieron algunos acontecimientos con el grito de independencia de las naciones colonizadas por la corona española ${ }^{3}$

Se debatió las causas generales de la independencia Hispanoamericana, donde empieza a aparecer uno de los hechos que ha causado mayor debate en la comunidad académica como lo es la expulsión de los jesuitas. La compañía de Jesús que tenía una misión colonizadora al interior de las colonias hispanas, tenían una ventaja con respecto a las autoridades coloniales, la cual era que ante el arraigo católico tan marcado en la colonia, los misioneros o evangelizadores, contaban con más apoyo popular y tenían una alta credibilidad entre los creyentes, después de todo ellos predicaban la palabra del ser todo poderoso que en ultimas era superior a la autoridad del rey y de la corona, además los jesuitas, al ser personas letradas, tenían la oportunidad de acceder a ciertos conocimientos y teorías consideradas libertarias, por lo que ante la expulsión de las Américas, no es para nada raro que ellos hubiesen colaborado con ideas de revolución en los criollos y se haya creado un ambiente de zozobra en el cual el rey está en contra de Dios y de sus ministros. ${ }^{4}$

Otra causa repetitiva en la mayoría de sucesos ocurridos en gran parte de las colonias, era la participación criolla en los cabildos, en lo que pueden ser vestigios de participación popular en la colonia, vemos como los hijos de españoles nacidos en las Américas, empiezan a ganar protagonismo en el escenario local ya que al empezar a ilustrarse, son estos los que entablan un deseo de poder, al democratizar la participación local en las Américas, se genera un escalón de poder para los criollos. ${ }^{5}$ hispanoamericana", Ediciones cultura hispánica, Madrid, 1953

$5 \quad$ Ibídem (comisión primera sección segunda)

Ibídem (comisión primera, sección tercera) 


\section{REVISTA VIRTUAL VIA INVENIENDI ET IUDICANDI \\ "CAMINO DEL HALLAZGO Y DEL JUICIO"}

http://viei.usta.edu.co/ E-MAIL: revistainveniendi@usantotomas.edu.co

Además, otros acontecimientos muy cercanos a lo anterior, fueron el poder de las nuevas aristocracias americanas y su poderío y los feudalismos en América. Era un hecho para la época que en América se crearon grupos de grandes latifundistas que cada vez querían debido a su poderío económico más participación en las decisiones públicas y de la corona que en cierta medida afectaban sus propiedades y negocios; sumado a esto, los hijos de estos hacendados, se educaban en las universidades europeas lo que los hacía receptores de primer orden de los avances de la ciencia y de la tecnología en el mundo occidental y las nuevas ideas políticas y económicas que se divulgaban en las grandes urbes de Europa.

La invasión Napoleónica a España, es sin duda uno de los elementos históricos más importantes y en nuestro criterio, uno de los más influyentes de lo sucedido hace 200 años por las tierras americanas. La guerra que se dio en España que trajo consigo el derrocamiento de Fernando VII de su credencial de rey de España y se produjo una anexión de esta ultima al imperio que creo Napoleón como soberano absoluto de Francia y las tierras conquistadas. Esa falta de poder de Fernando VII y la promoción de su revolución fue inminente mente ejemplo para lo que sucedía en América. ${ }^{6}$

Inglaterra, venía de perder su dominio sobre los Estados Unidos de Norteamérica, además había librado una dura batalla contra Francia y España, por lo que su economía para la época no era la optima, sumado a esto con las Américas bajo el poder Español le era más difícil el comercio de sus productos y la exportación a bajos costos de las materia primas que se extraían en la América hispánica. igualmente, en varios capítulos de la historia hemos visto como los denominados próceres de la Independencia de los distintos países hispánicos acudían a la corona inglesa en búsqueda de instrucción militar, armas y financiación para librar guerras independentistas contra España, como fue el ejemplo de El General 


\section{REVISTA VIRTUAL VIA INVENIENDI ET IUDICANDI \\ "CAMINO DEL HALLAZGO Y DEL JUICIO"}

http://viei.usta.edu.co/ E-MAIL: revistainveniendi@usantotomas.edu.co

Francisco Miranda, personaje que consideramos de alta trascendencia en las independencias latinoamericanas, hacia 1797 planeo la independencia de las naciones del norte de Sudamérica, con el apoyo de otros criollos notables, Estados Unidos y el Reino de Inglaterra ${ }^{7}$

Sin embargo, los planes ingleses también se dirigían a desestabilizar el gobierno Francés en España instaurado por Napoleón ${ }^{8}$ cosa que sin embargo no le resta importancia a la influencia Inglesa en las revoluciones.

Con las guerras que la corona Española libraba en Europa, mas las reformas borbónicas que aumentaron los impuestos en gran parte del territorio de las colonias lo que genero un clima de protesta, el desabastecimiento de las importaciones desde España a América, y la crisis en la economía española trajo para las colonias la necesidad de abrir comercio con otros países como Estados Unidos e Inglaterra y el malestar de los criollos de que los virreinatos tuvieran que en cierta medida subsidiar las guerras de independencia de la corona española, el poderío económico de la corona estaba ampliamente diezmado. ${ }^{9}$

A los anteriores hechos, es necesario agregarle los movimientos ideológicos que se gestaban en el siglo XVIII, el cual fue el tema principal de estudio de la comisión segunda en el Congreso Hispanoamericano de Historia, y que se resume principalmente en el enciclopedismo ilustrado y la revolución francesa. ${ }^{10}$ Ideas que se difundían en la academia, en los libros y la prensa y fueron tenidas en cuenta por los criollos ilustrados y por las revoluciones de los españoles contra los franceses, bajo las premisas de igualdad, libertad y fraternidad, que tanto eco

7 RUMAZO, González Alfonso, Francisco de Miranda "Protolider de la Independencia americana", Editorial Intermedio, Bogotá, 2006

$8 \quad$ Gutierrez Ardila, Daniel, Revolución y Diplomacia "El caso de la primera junta de Quito

(1809)" Editorial Red Fronteras de la Historia, Quito. 2009

10 Congreso Hispanoamericano de Historia, Ibídem (Comisión primera, sección quinta)

Ibídem (Comisión segunda, sección tercera) 


\section{REVISTA VIRTUAL VIA INVENIENDI ET IUDICAND\|}

"CAMINO DEL HALLAZGO Y DEL JUICIO"

http://viei.usta.edu.co/ E-MAIL: revistainveniendi@usantotomas.edu.co

tuvieron en la burguesía criolla al estar exentos de los principales poderes políticos en los virreinatos.

Para cerrar este primer capítulo, queremos compartir las conclusiones a las que se llego en aquel congreso y que resumen en buena parte las causas de la independencia de los pueblos hispánicos:

"La revolución americana no es un episodio aislado cuya explicación no deba buscarse en la brusca actuación de una o varias causas concretas, sino un proceso espiritual complejo, vinculado a la historia universal..."

A) Difusión de las teorías enciclopedistas:

Proclamación de los derechos del hombre, así como la influencia de EEUU e Inglaterra para poder entrar a comerciar con las indias dando a conocer esas ideas (nacionalismo, constitucionalismo y republicanismo). El arte gótico y barroco, el despotismo, la masonería (en las junta regentes). Además en los colegios y universidades criollas se estudiaban estos principios junto con la constitución de filadelfia.

B) Hegemonía del mando de los españoles peninsulares, dando lugar al odio de los criollos:

La proclamación de la constitución de Cádiz, la junta regente con desigualdad de representantes desconociendo el numero de las poblaciones. Los criollos eran impotentes al no poder ocupar grandes cargos por el hecho de ser criollos. Las leyes hispánicas y de indias no hacían diferencia entre criollos y españoles ya que para reconocían la nacionalidad por vinculo sanguíneo. Los atropellos derivaban principalmente de los gobernantes peninsulares que de la misma metrópoli. Las juntas de Gobierno. 


\section{REVISTA VIRTUAL VIA INVENIENDI ET IUDICAND\|}

"CAMINO DEL HALLAZGO Y DEL JUICIO"

http://viei.usta.edu.co/ E-MAIL: revistainveniendi@usantotomas.edu.co

C) Graves errores de la política seguida por la península y su decadencia política mundial:

Expulsión de los jesuitas, reformas borbónicas y tratados internacionales para la guerra. Un error fue el apoyo de la corona a EEUU para lograr su independencia por los enemigos y el ejemplo dado a América, el mal manejo de las finanzas en la corona, existían excesos del rey Fernando VII, la invasión de Napoleón

D) La agitación sembrada por Inglaterra y Francia, deseosas de destruir, en provecho propio el imperio español:

Las potencias buscaban disfrutar de los monopolios de España, apoyo militar, financiero e ideológico, las palabras de Napoleón y su no oposición a la independencia de las colonias americanas

E) El recio individualismo de la raza hispánica:

Los pobladores se auto determinaban por su lugar de origen e interpretaban las ideas y nuevas filosofías de acuerdo a su contexto y entorno. Se diferencian plenamente entre hispanos y americanos. Los españoles desarraigados de su tierra se sentían autóctonos en las Américas. El criollo se sentía además con el derecho de explotar América por ser descendientes directos de los descubridores

\section{Causas de la independencia del Nuevo Reino de la Nueva Granada}

cada uno de los sucesos desarrollados en las páginas anteriores bajo la denominación de cusas de la independencia Hispanoamericana, también se 


\section{REVISTA VIRTUAL VIA INVENIENDI ET IUDICAND\|}

"CAMINO DEL HALLAZGO Y DEL JUICIO"

http://viei.usta.edu.co/ E-MAIL: revistainveniendi@usantotomas.edu.co

pueden transcribir dentro de las causas de la independencia de Colombia, ya que el Nuevo Reino de la Nueva Granada, no fue ajeno a los movimientos sociales mundiales y mucho menos ajeno a lo que se viva al interior de España y de América, para tener clara la relación de los hechos con la consecuencia final, el acta del 20 de julio de 1810, desarrollaremos el tema bajo los dos ítems propuestos, a) causas externas, b) Causas internas.

a) Causas externas:

Definitivamente los hechos anotados en las causas de la independencia de los países Hispanoamericanos son causas externas de la independencia granadina, pero de acuerdo a la investigación que desarrollamos al interior del semillero de investigación, creemos que su relación de causalidad se dio por distintos hechos así:

- Independencia de los Estados Unidos:

La declaración de independencia de los Estados Unidos de Norteamérica, fue un suceso de gran repercusión en el ideario de independencia criolla, con la emancipación del país norteño, se creó un clima al interior de la Nueva Granada, de la posibilidad de libertad de orden económico y político, era el ejemplo claro de que los criollos dejarían de pagar impuestos para el provecho del a corona y de ocupar los anhelados altos puestos políticos, para pasar a una reinversión de que lo pagado en Nueva Granada, se queda en Nueva Granada y que es posible el auto gobierno y no la administración de los españoles.

También, esta independencia sirvió para que los pueblos hispánicos, incluida Nueva Granada estrecharan lasos de comercio con Inglaterra ya que esta potencia había perdido su colonia que era fuente de materias primas y objeto de exportaciones.

- La ilustración 


\section{REVISTA VIRTUAL VIA INVENIENDI ET IUDICANDI \\ "CAMINO DEL HALLAZGO Y DEL JUICIO"}

http://viei.usta.edu.co/ E-MAIL: revistainveniendi@usantotomas.edu.co

El movimiento ideológico que revoluciono la historia de principios del siglo XIX, llego al Reino de la Nueva Granada a través de los centros de enseñanza y la traducción de los derechos del hombre y del ciudadano por parte de Antonio Nariño, lo que permitió a los criollos letrados principalmente, tener una visión amplia de una revolución burgués.

Además, el contenido de estas ideas, que en su contexto buscaban la abolición del régimen monárquico francés y que fue el mismo soporte ideológico tomado por Fernando VII para recuperar la península Ibérica del dominio de Napoleón, representaban idearios similares a lo que en últimas buscaban los criollos en la Nueva Granada.

\section{- La Junta de Quito}

En la ciudad de Quito, los criollos quiteños, en un intento de emancipación, prepararon una junta, la cual tenía como propósito, aprovechar la guerra que se vivía en España con el ejército de Napoleón para proclamar la independencia, de esta ciudad vinieron a Santa Fe algunos quiteños para promover la creación de su similar en esta ciudad. Para su divulgación aprovecharon las tertulias y cafés capitalinos y así vender una idea de revolución.

\section{- Francisco de Miranda}

Definitivamente, el General Francisco de Miranda fue una persona clave para la independencia colombiana. Este caraqueño que actuó en la guerra de independencia Norteamericana y en la revolución francesa lo que le ha perpetuado un lugar en el Arco del Triunfo en los campos elicios parisnos, fue el ideario de "el manifiesto de parís" que no es otra cosa que una estrategia de 


\section{REVISTA VIRTUAL VIA INVENIENDI ET IUDICAND\|}

"CAMINO DEL HALLAZGO Y DEL JUICIO"

http://viei.usta.edu.co/ E-MAIL: revistainveniendi@usantotomas.edu.co

independencia dirigida a libertar Sudamérica y en especial al Nuevo Reino de Nueva Granada que era su terruño. Miranda emprendió un fallido intento de campaña libertadora hacia 1806. Miranda dejo una sensación de revolución y además puso a tono a Francia, Estados Unidos e Inglaterra de la posibilidad de independencia de las colonias americanas, de ahí la influencia que nosotros encontramos al proceso interno de emancipación.

\section{- La guerra de independencia de España}

Ya lo habíamos reseñado como una causa general en América, sin embargo, esto tuvo amplia repercusión dentro de la Nueva Granada, ya que queremos insistir, fue la misma España la que dio ejemplo de que los pueblos deben ser gobernados por sus asociados y no tienen porque soportar una administración extranjera. Por los costos de la guerra y los lujos de la corona ya años antes se habían implementado las reformas borbónicas que produjeron el levantamiento comunero en la ciudad del Socorro, Santander.

Ante la pérdida del poder de Fernando VII, se crearon juntas como la de Cádiz, en la cual la representación criolla era mínima, en comparación a la representación Ibérica, lo que dejaba en entredicho las desigualdades con las que se trataban los pueblos colonizados. Conjuntamente, los criollos que fueron engañados por don José Acevedo y Góngora con el antecedente del levantamiento comunero, no estaban de acuerdo en aportar a la financiación de una guerra, cuando no la sentían propia.

- Las demás revoluciones

Los levantamientos populares en los demás pueblos Americanos y las noticias de revolución alimentaban cada día más el sentimiento granadino de revolución. 


\section{REVISTA VIRTUAL VIA INVENIENDI ET IUDICAND\|}

"CAMINO DEL HALLAZGO Y DEL JUICIO"

http://viei.usta.edu.co/ E-MAIL: revistainveniendi@usantotomas.edu.co

Como vimos en estas causas externas de la independencia colombiana, que consideramos las principales, vemos que lo que alimentaron principalmente fue el sentimiento de libertad en los granadinos y un aliento de que se puede lograr la independencia de la corona, lo que simplemente lleno de valor a la burguesía colonial. La socialización de las teorías extranjeras es en resumida cuenta la causa externa de la independencia del Nuevo Reino de Nueva Granada.

b) Causas Internas

Son muchos los acontecimientos que se hablan alrededor de las causas internas de la independencia de Colombia, en este punto nos queremos concentrar en hacerle un comentario a la posible relación de causalidad de muchas de los nombrados hechos, pero nos interesa más, que nuestro lector haga una reflexión de la relación que pudo haber tenido estas con el efecto el cual fue el acta del 20 de julio de 1810 y así dejar de una vez por todas algún tipo de ingenuidad acerca del grito de independencia y ver que no fue un hecho improvisado o aislado al acontecer nacional y mundial.

Nos parece importante aclarar que el orden de las causas expuestas no significan un grado de importancia o relevancia, ya que, como antes lo anotamos, la reflexión acerca de la causalidad, es un ejercicio que invitamos a hacer a nuestro lector, nosotros solo nos limitaremos a enunciarlas y dar nuestra relación de causalidad acorde con la investigación del semillero.

\section{- Revolución comunera}

La revolución comunera fue un movimiento gestado en los pueblos del hoy departamento del Santander, en el cual un grupo de criollos, se subleva contra la corona española por la imposición de impuestos producto de las reformas bubónicas. 


\section{REVISTA VIRTUAL VIA INVENIENDI ET IUDICAND\|}

"CAMINO DEL HALLAZGO Y DEL JUICIO"

http://viei.usta.edu.co/ E-MAIL: revistainveniendi@usantotomas.edu.co

Esta emancipación, no pretendía la independencia de la corona, solo un trato más digno por parte de las autoridades coloniales y que no se cobraran impuestos excesivos sobre todo a la producción e importación tabacalera que era el principal producto de exportación de Nueva Granada en la época.

Este levantamiento termino con la firma de las capitulaciones comuneras en la ciudad de Zipaquirá, por parte de los líderes criollos y la corona española en cabeza de don José Acevedo y Góngora, capitulaciones que nunca se cumplieron por parte de España. Es esto último lo que consideramos una causa de la independencia colombiana, ya que los principales personajes de esta revolución, fueron capturados por el ejército español o fueron asesinados y no tuvieron injerencia en los acontecimientos del 20 de julio.

Mas bien, a los criollos, les quedo una importante enseñanza y es que la corona española ya los había "traicionado" en alguna época de la historia y los líderes revolucionarios fueron perseguidos, por lo que tal vez lo aprendido era que si no lograban una verdadera emancipación, correrían la misma suerte comunera.

- La expedición Botánica

La expedición botánica, que fue una política implementada por el Virrey Don José Acevedo y Góngora, la cual buscaba recolectar, muestras de las plantas medicinales que habían en la Nueva Granada, fue adelantada por el español José Celestino Mutis y recorrió una importante zona del territorio granadino.

Para que Mutis realizara su denominada expedición, necesitaba un equipo de trabajo, el cual necesariamente tenía que ser letrado. Mutis, conocía de las ideas revolucionarias y en varios textos se atreven a afirmarlo, fue creador de una tertulia en Santa Fe, que se dedicaba al conocimiento de las ciencias. 


\section{REVISTA VIRTUAL VIA INVENIENDI ET IUDICAND\|}

"CAMINO DEL HALLAZGO Y DEL JUICIO"

http://viei.usta.edu.co/ E-MAIL: revistainveniendi@usantotomas.edu.co

La relación que encontramos con la independencia de Colombia, radica en que esta expedición genero inquietud en los criollos por educarse, en términos más coloquiales, Mutis y sus colaboradores impusieron la moda de aprender de matemáticas, biología, botánica y ciencias en Santa Fe y en cada uno de los lugares en donde estuvo la expedición. Recordemos que los últimos días de Mutis los dedico a la enseñanza de las ciencias.

\section{- Los colegios en Santa Fe}

En la capital, para la época, existían dos centros importantes de enseñanza que eran fuente de conocimiento para los criollos, El colegio del Rosario administrado por la Orden de Predicadores y el Colegio San Bartolomé de los padres Jesuitas.

Estos centros de enseñanza permitieron que los criollos aprendieran a leer y escribir y se acercaran a las ciencias naturales y sociales. El colegio del Rosario de los padres Dominicos, fue de corte más conservador ya que por política de los padres, solo se permitía la enseñanza de temas que eran concertados con la corona española; mientras que, en el San Bartolomé, lugar donde mutis enseño sus descubrimientos, la enseñanza era mucho más liberal y se podía tener acceso a las ideas enciclopedistas y otros temas considerados revolucionarios en la época.

A pesar de que en el San Bartolomé se hacían tertulias donde se imaginaba una nación libre, la importancia de los colegios fue el letrar a los criollos, haciendo de estos una burguesía preparada y con capacidad de análisis y entendimiento de las causas sociales.

- Las Tertulias 


\section{REVISTA VIRTUAL VIA INVENIENDI ET IUDICAND\|}

"CAMINO DEL HALLAZGO Y DEL JUICIO"

http://viei.usta.edu.co/ E-MAIL: revistainveniendi@usantotomas.edu.co

En Santa Fe, varios criollos ilustres, crearon las famosas tertulias en las cuales se citaban varias personas para compartir los nuevos conocimientos en ciencia política y derecho que se difundían en los centros de enseñanza de Estados Unidos y Europa.

En estas tertulias varios personajes como el Antonio Nariño, el General Francisco de Paula Santander y Camilo Torres hablaban de postulados de libertad e igualdad al mismo tiempo que planeaban como lograr una posible emancipación de la corona y hacer de la Nueva Granada una nación soberana e independiente.

En esos cafés, bajo un ambiente de camaradería, bajo un ejercicio de dialéctica y hermenéutica, se intercambiaron ideas de revolución y se socializaron las nuevas tendencias del norte del continente, del enciclopedismo francés y el sentimiento español de auto gobernarse y librarse de la invasión francesa, para nosotros es indudable que este tipo de tertulias creaban un ambiente y un sentimiento entre los pobladores de Santa Fe que apuntaba hacia una emancipación.

- Periódicos, revistas y publicaciones en El Nuevo Reino de Nueva Granada

En este aparte de las causas internas de la independencia de Colombia, se debe hacer una especial mención al Cubano Manuel del Socorro Rodríguez, considerado el fundador del periodismo en Colombia, ${ }^{11}$ para nosotros esta es una causa importante de la independencia ya que a pesar de que el periodismo en Nueva Granada no era de tipo revolucionario, no deja de ser un medio de difusión de ideas, en las cuales existe un debate político y una opinión.

El Papel Periódico de la Ciudad de Santa Fe, fue el primer periódico oficial de la capital del virreinato en 1791, bajo la salvedad que ya en 1785 se habían hecho

11 OTERO Muñoz, Gustavo, "Historia del periodismo en Colombia" Bilblioteca Aldena de Colombia, 1936, Bogotá, Colombia 


\section{REVISTA VIRTUAL VIA INVENIENDI ET IUDICAND\|}

"CAMINO DEL HALLAZGO Y DEL JUICIO"

http://viei.usta.edu.co/ E-MAIL: revistainveniendi@usantotomas.edu.co

dos publicaciones que solo tuvieron una edición llamados el Aviso del Terremoto y la Gaceta Oficial de Santa Fe.

En varios de estos periódicos que se publicaron en tiempos de la colonia, personajes como Antonio Nariño hicieron publicaciones que les costaron penas como el destierro. $\mathrm{Y}$ aunque ya lo dijimos, no eran de corte revolucionario, en varios de publicaciones de denunciaban atropellos e injusticias del virreinato para con los criollos.

\section{CONCLUSIÓNES.}

La recopilación de las causas de la Independencia bajo un estudio de causalidad, esto es bajo la regla Causa - Efecto, es una tarea que se ha emprendido por distintos autores y que suscita varias discusiones de tipo académico ya que no basta con que hayan ocurrido unos hechos en vísperas del acta del 20 de julio de 1810, también se debe establecer la influencia directa que esos hechos tuvieron con el sentimiento de libertad, revolución e independencia de los pobladores del virreinato.

Lo que tratamos de hacer a lo largo de estas páginas, fue una propuesta reflexiva de tipo académico que busque crearle al lector una motivación por conocer la historia de nuestra patria y como un conjunto de sucesos internos y externos llevan a lograr algo tan preciado por un pueblo como es su soberanía.

La discusión está abierta, nuestras reflexiones están ahí, solo queda la invitación por hacer el ejercicio pedagógico para conocer y discutir acerca de las causas que motivaron el levantamiento de los criollos plasmado en el acta del 20 de julio de 1810. 


\section{REVISTA VIRTUAL VIA INVENIENDI ET IUDICANDI \\ "CAMINO DEL HALLAZGO Y DEL JUICIO"}

http://viei.usta.edu.co/ E-MAIL: revistainveniendi@usantotomas.edu.co

\section{BIBLIOGRAFIA:}

- Congreso Hispanoamericano de Historia, "CAUSAS, CARACTERÍSTICAS DE LA INDEPENDENCIA", ediciones Cultura Hispánica, Madrid España, 1953

- CAICEDO, Luis Javier, "1810 - 2010 Bicentenario de la Independencia de Colombia y Latinoamericana" editorial Artes y Letras LTDA. Medellín, Colombia 2005

- RuMAzO, González Alfonso, Francisco de Miranda "Protolider de la Independencia americana", Editorial Intermedio, Bogotá, 2006

- GUTIERREZ Ardila, Daniel, Revolución y Diplomacia "El caso de la primera junta de Quito (1809)" Editorial Red Fronteras de la Historia, Quito. 2009

- OTERO Muñoz, Gustavo, "Historia del periodismo en Colombia" Biblioteca Aldena de Colombia, 1936, Bogotá, Colombia

- PALACIOS, Marco, "Las consecuencias económicas de la independencia en Colombia: sobre los orígenes del subdesarrollo", lustraciones: Colecciones Biblioteca Luis-Ángel Arango, Bogotá

- BEBOYA F, Victor, "independencia y república con bases fundamentales en la colonia", Editorial Libreria Stella, Bogotá, 1944

- GOMÉZ Hoyos, Rafael, "La independencia de Colombia" Editorial MAPFRE, Madrid, 1992

- GRANADOS, Rafael María, "prehistoria, conquista, colonia, independencia y República”, Imprenta Departamental Antonio Nariño, Bogotá, 1978

- OLIVEROS Lombana, Andrés "coyuntura revolucionaria y revuelta popular (1808-1810)", panamericana Editorial, Bogotá, 1999

- POSADA, Eduardo, "Capítulos sobre la revolución de 1810" Imprenta Arboleda y Valencia, Bogotá, 1914

- bicentenarioindependencia.gov.co/ Alta Consejería Presidencial para el Bicentenario de la Independencia de Colombia,

- lablaa.org/bibliotecavirtual/ Biblioteca Virtual Luis Ángel Arango blaa.digital 


\section{REVISTA VIRTUAL VIA INVENIENDI ET IUDICAND\| \\ "CAMINO DEL HALLAZGO Y DEL JUICIO"}

http://viei.usta.edu.co/ E-MAIL: revistainveniendi@usantotomas.edu.co

- remoto.usta.edu.co/acceso_biblioteca/ Red de bibliotecas de la Universidad Santo Tomas, Acceso Remoto Para Usuarios. 